\title{
Vehicle Kinematics in TURNS AND the ROLE OF CORNERING LAMPS IN DRIVER VISION
}

\author{
JOHN M. SULLIVAN \\ Michael J. FLanNagan
}

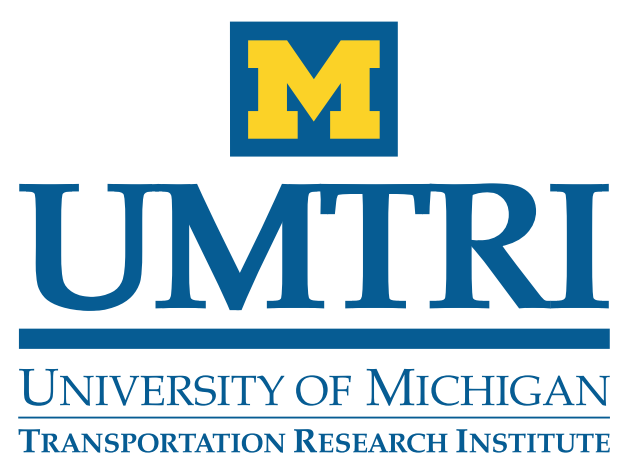


Vehicle Kinematics in Turns and the Role of Cornering Lamps in Driver Vision

\author{
John M. Sullivan \\ Michael J. Flannagan
}

The University of Michigan

Transportation Research Institute

Ann Arbor, Michigan 48109-2150

U.S.A.

Report No. UMTRI-2010-32

November 2010 


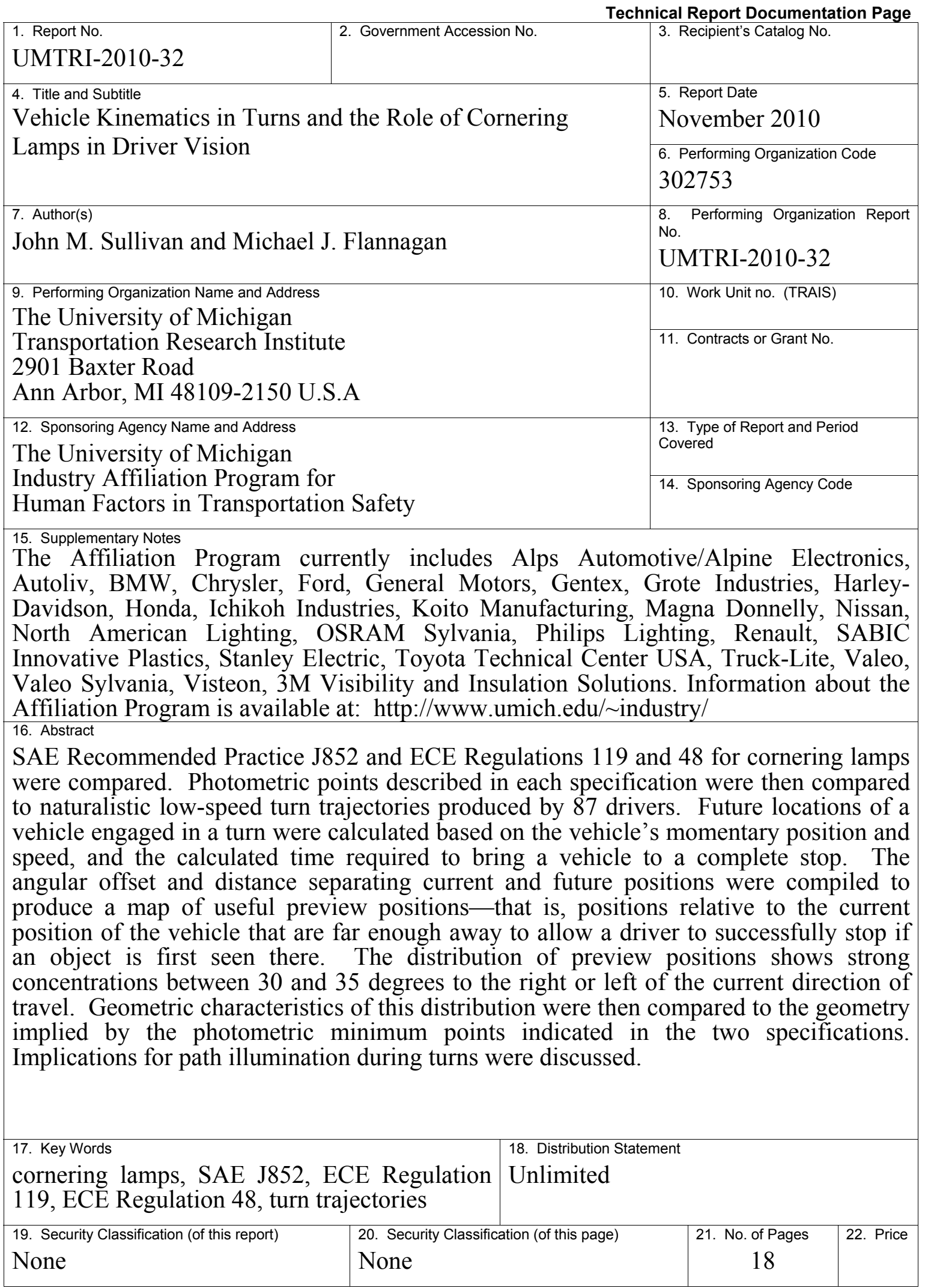




\section{Acknowledgements}

Appreciation is extended to the members of the University of Michigan Industry Affiliation Program for Human Factors in Transportation Safety for support of this research. The current members of the Program are:

Alps Automotive/Alpine Electronics
Autoliv
BMW
Chrysler
Ford
General Motors
Gentex
Grote Industries
Harley-Davidson
Honda
Ichikoh Industries
Koito Manufacturing
Magna Donnelly

Nissan

North American Lighting

OSRAM Sylvania

Philips Lighting

Renault

SABIC Innovative Plastics

Stanley Electric

Toyota Technical Center, USA

Truck-Lite

Valeo

Valeo Sylvania

Visteon

3M Visibility and Insulation Solutions 


\section{Contents}

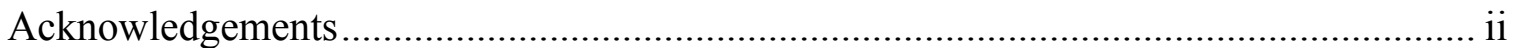

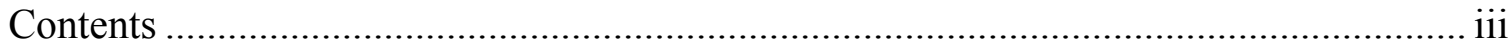

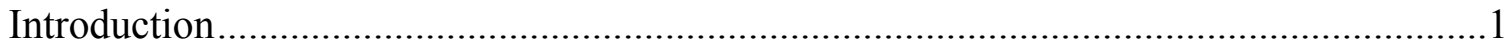

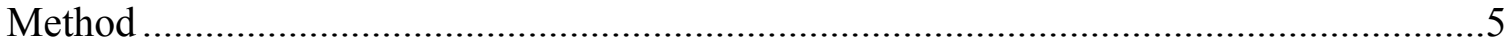

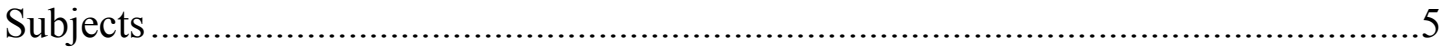

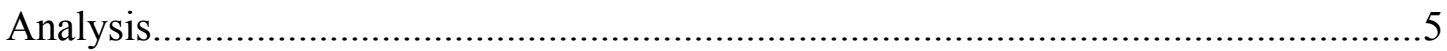

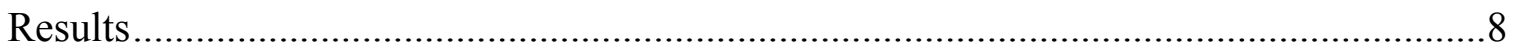

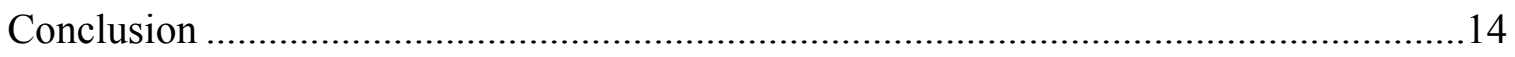

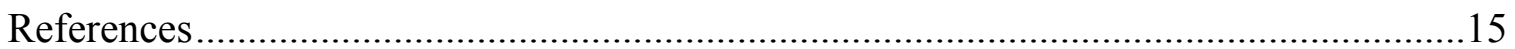




\section{Introduction}

Cornering lamps were first featured on US automobile lines in the early 1960's, appearing on the Cadillac DeVille in 1962. The feature later migrated to models offered by other General Motors divisions such as Buick, Oldsmobile, and Pontiac later in the decade (citation). The 1962 Cadillac DeVille brochure (The Old Car Manual Project, 2010) describes the feature as projecting “...a 30 degree fan shaped 50-candle power beam, perpendicular to the side of the car, thus illuminating the roadside and road signs for extra safety in turning corners at night." The feature eventually appeared on models offered by Ford in 1966, and Chrysler in 1968. European manufacturers did not offer cornering lamps until after 2005, when ECE Regulation No. 119 (ECE R119; United Nations Economic Commission for Europe, 2005) was adopted, although the 1967 Citroën DS did feature a swiveling headlamp to help illuminate turns. Japanese manufacturers began offering cornering lights in the late 1980's. Today, cornering lamps are frequently offered as standard equipment on many luxury-class vehicles, and are offered by most worldwide manufacturers. Cornering lamp functionality can be found embedded within sophisticated adaptive frontlighting systems (AFS) (e.g., 2010 BMW Series 1), combined with fog lamps (e.g., 2011 Volkswagen Touareg) or implemented as a separate lighting function (e.g., 2010 Cadillac DTS).

This report examines the recommended characteristics of the illumination function of front cornering lamps as described in the Society of Automotive Engineers Recommended Practice J852 (SAE J852), Front Cornering Lamps for Use on Motor Vehicles (Society of Automotive Engineers, 2001), and ECE R119/48, Uniform Provisions Concerning the Approval of Cornering Lamps for Power-Driven Vehicles/ Uniform Provisions Concerning the Approval of Vehicles with Regard to the Installation of Lighting and Light-Signalling Devices (United Nations Economic Commission for Europe, 2005, 2008). The recommended light distributions for cornering lamps will then be compared to low-speed turn maneuvers observed during naturalistic driving to determine how well the recommendations fit a driver's illumination needs over the path of the turn. It is important to note that cornering lamps also likely provide useful illumination unrelated to turn trajectory. For example, when turning into a driveway, 
illumination of out-of-path objects can help drivers notice potential future conflicts with pedestrians; when stopped at an intersection a vehicle's cornering lamps can help illuminate pedestrians in crosswalks; when driving along a dark road searching for a turnoff, cornering lights may improve drivers' awareness of the roadway edge. The present analysis does not explicitly address these cornering scenarios; it does, however, address the illumination needs implied in an active turn maneuver and is consistent with cornering illumination activated by either steering wheel angle or yaw rate sensing.

Front Cornering Lamp Photometry and Operation. A direct comparison between SAE J852 and ECE R119/48 is provided in Table 1. Notably, the documents differ in the use of reference coordinates describing the photometric output of the cornering lamp: SAE J852 uses an axis perpendicular to the vehicle's longitudinal axis; ECE R119's axis is parallel to this axis. In US models of the 1960's through the 1980's, cornering lamps were commonly mounted on the left and right front fenders, forward of the front wheel well (Figure 1). The axis of a cornering lamp was thus originally perpendicular to the vehicle axis. In later designs, the lamp is positioned farther forward and nearer to the front headlamps (Figure 2). In European models, the cornering function is closely related to adaptive frontlighting system (AFS) function and may be integrated directly into the forward lighting assembly (e.g., 2010 Renault Modus, Clio III) or associated with fog lamp operation (e.g., 2010 BMW Series 3).

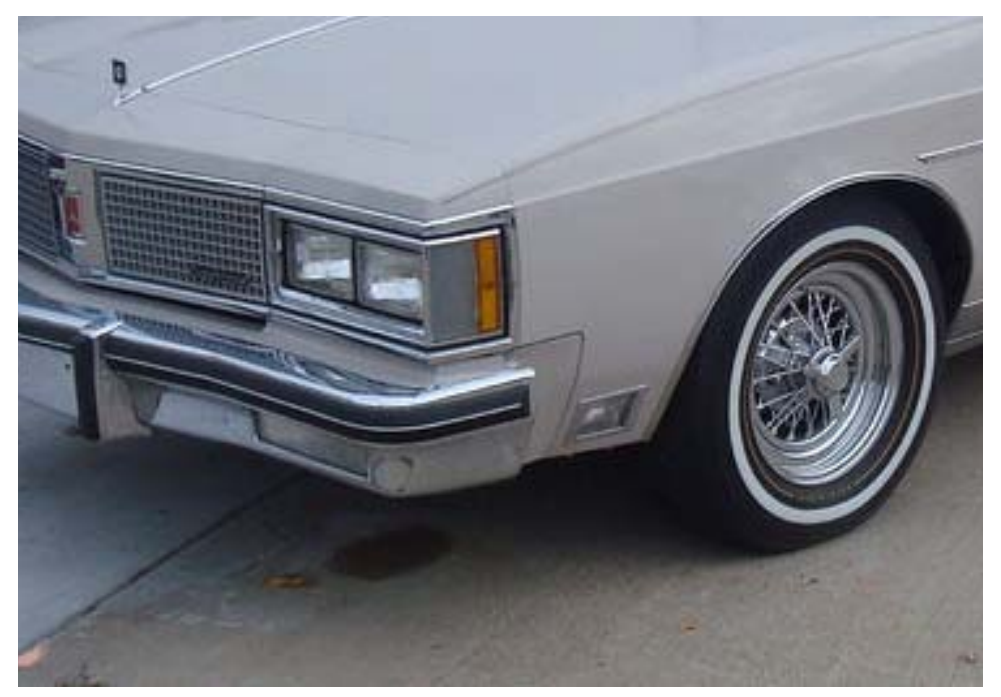

Figure 1. 1983 Oldsmobile 98 cornering lamp. 


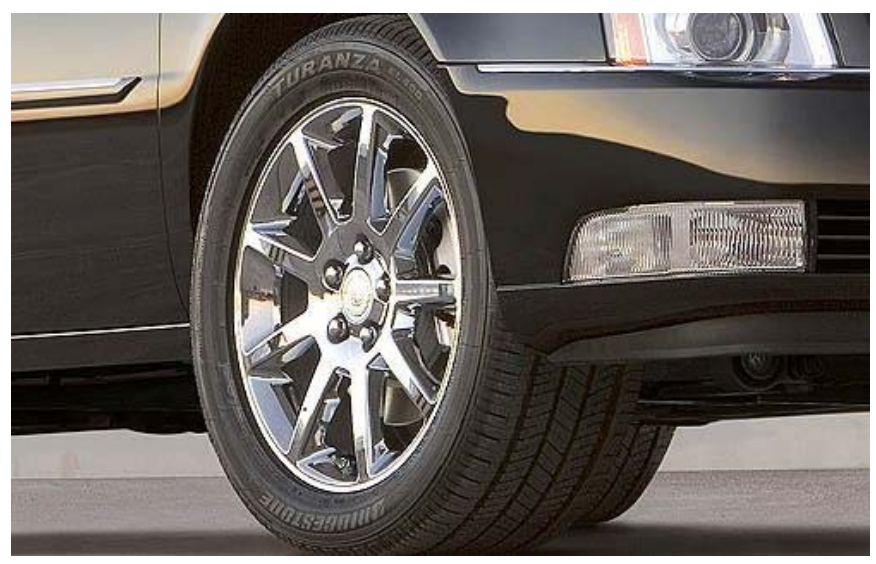

Figure 2. 2009 Cadillac DTS. Cornering lamps are positioned below headlamps in the forward front corners of the vehicle.

Other notable differences between the two documents include generally lower photometric minimums at the specified test points and lower maximums at $\mathrm{H}$ in ECE R119, although higher maximums seem to be acceptable in the 10-90 U range surrounding the lamp. ECE R48 also allows a generally wider range of lamp mounting heights, although the regulation further restricts mounting height not to exceed the height of the dipped beam. ECE R48 is also more specific about the acceptable speed range for cornering lamp activation, recommending activation only at speeds below $40 \mathrm{~km} / \mathrm{h}$. In contrast, US automobile manufacturers seem to have adopted $35 \mathrm{mph}(56 \mathrm{~km} / \mathrm{h})$ as their definition of low-speed. Other criteria for activation are similar in the two documents, although the steering angle criterion is not specific. Finally, criteria for lamp deactivation are similar between the two documents, with exception of the role of vehicle speed in deactivating the lamp. The SAE recommended practice suggests that the lamp may be deactivated when speed becomes high or if the vehicle is stopped "to avoid discomfort to other road users." ECE R48 is comparatively firmer on this point and requires deactivation only above $40 \mathrm{~km} / \mathrm{h}$. 
Table 1

Comparison between SAE J852 and ECE Regulations 119 and 48.

\begin{tabular}{|c|c|c|c|}
\hline Characteristic & SAE J852 & ECE Regulation 119 \& 48 & Notes \\
\hline Photometry & $\begin{array}{l}\text { Minimums (left): } \\
2.5 \mathrm{D}-30 \mathrm{~L}: 300 \mathrm{~cd} \\
2.5 \mathrm{D}-45 \mathrm{~L}: 500 \mathrm{~cd} \\
2.5 \mathrm{D}-60 \mathrm{~L}: 300 \mathrm{~cd} \\
\text { Maximums (left): } \\
10 \mathrm{U} \text { to } 90 \mathrm{U}-5 \text { to } 135 \mathrm{~L}: 125 \mathrm{~cd} \\
4 \mathrm{U}-5 \text { to } 135 \mathrm{~L}: 200 \mathrm{~cd} \\
2 \mathrm{U}-5 \text { to } 135 \mathrm{~L}: 300 \mathrm{~cd} \\
1 \mathrm{U}-5 \text { to } 235 \mathrm{~L}: 400 \mathrm{~cd} \\
0 \mathrm{U}-5 \text { to } 235 \mathrm{~L}: 500 \mathrm{~cd}\end{array}$ & $\begin{array}{l}\text { Minimums (left): } \\
2.5 \mathrm{D}-30 \mathrm{~L}: 240 \mathrm{~cd} \\
2.5 \mathrm{D}-45 \mathrm{~L}: 400 \mathrm{~cd} \\
2.5 \mathrm{D}-60 \mathrm{~L}: 240 \mathrm{~cd} \\
10 \mathrm{U} \text { to } 10 \mathrm{D}-30 \mathrm{~L} \text { to } 60 \mathrm{~L}: 1 \mathrm{~cd} \\
\text { Maximums(left): } \\
0 \text { to } 90 \mathrm{U}-\mathrm{L} \text { and R: } 300 \mathrm{~cd} \\
.57 \mathrm{D}-\mathrm{L} \text { and R: } 600 \mathrm{~cd} \\
\text { Below } .57 \mathrm{D}-\mathrm{L} \text { and R: } 10,000\end{array}$ & $\begin{array}{l}\text { The original reference } \\
\text { axis in the SAE } \\
\text { recommended practice is } \\
\text { perpendicular to } \\
\text { longitudinal axis of the } \\
\text { vehicle. The SAE } \\
\text { coordinates have been } \\
\text { converted to the reference } \\
\text { axis used in ECE R119, } \\
\text { the longitudinal axis of } \\
\text { the vehicle. } \\
\text { Specification is given for } \\
\text { the driver side (left) } \\
\text { lamps; to convert to } \\
\text { passenger side (right) } \\
\text { coordinates, left angular } \\
\text { offsets should be changed } \\
\text { to right. }\end{array}$ \\
\hline $\begin{array}{l}\text { Mounting } \\
\text { Height }\end{array}$ & $\begin{array}{l}\text { Minimum: } 305 \mathrm{~mm} \\
\text { Maximum: } 760 \mathrm{~mm}\end{array}$ & $250 \mathrm{~mm}$ & $\begin{array}{l}\text { ECE R48 stipulates that } \\
\text { cornering lamp mounting } \\
\text { height cannot exceed } \\
\text { height of dipped beam } \\
\text { (United Nations } \\
\text { Economic Commission } \\
\text { for Europe, 2008). }\end{array}$ \\
\hline & $\begin{array}{l}\text { Activated if all the following } \\
\text { conditions are met: } \\
\text { Headlamps = ON }\end{array}$ & $\begin{array}{l}\text { Activated if all the following } \\
\text { conditions are met (ECE R48): } \\
\text { Headlamps = ON }\end{array}$ & $\begin{array}{l}\text { Many US manufacturers } \\
\text { define low vehicle speed } \\
\text { as less than } 35 \mathrm{mph}(56 \\
\mathrm{km} / \mathrm{h} \text { ). }\end{array}$ \\
\hline Activation & $\begin{array}{l}\text { Direction indicator }=\text { ON } \\
\text { AND } / \text { OR } \\
\text { Steering Angle = NOT Straight } \\
\text { Vehicle speed = "Low" }\end{array}$ & $\begin{array}{l}\text { Direction indicator }=\mathrm{ON} \\
\text { AND } / \mathrm{OR} \\
\text { Steering angle }=\text { NOT Straight } \\
\text { Vehicle Speed }<40 \mathrm{~km} / \mathrm{h}\end{array}$ & \\
\hline Deactivation & $\begin{array}{l}\text { Deactivated if any of the } \\
\text { following conditions are true: } \\
\text { Headlamps = OFF } \\
\text { (Direction Indicator = OFF } \\
\text { AND/OR } \\
\text { Steering Angle = Straight) } \\
\text { (Optional) } \\
\text { Vehicle Speed is high. } \\
\text { Vehicle is stopped. }\end{array}$ & $\begin{array}{l}\text { Deactivated if any of the } \\
\text { following conditions are true: } \\
\text { Headlamps }=\text { OFF } \\
\text { (Direction Indicator }=\text { OFF } \\
\text { AND } / O R \\
\text { Steering Angle }=\text { Straight) } \\
\text { Vehicle Speed }>40 \mathrm{~km} / \mathrm{h}\end{array}$ & \\
\hline
\end{tabular}




\section{Method}

The trajectories of naturalistic turning behavior were compiled for 87 drivers participating in the Road Departure Crash Warning (RDCW) field operational test (LeBlanc et al., 2006). For each driver, low speed turns were selected in which vehicle speed was less than $56 \mathrm{~km} / \mathrm{h}(35 \mathrm{mph})$ throughout the turn, and a heading change of between 45 and 150 degrees occurred from the start to the finish of the turn. For each point in the trajectory, a stopping time was calculated based on an estimated brake reaction time of 1.5 seconds, and a uniform deceleration rate of $0.3 \mathrm{~g}\left(2.94 \mathrm{~m} / \mathrm{s}^{2}\right)$ from the current speed of the vehicle. The future vehicle position at this time offset was then used to calculate an angular offset and distance from the current vehicle position. Thus, the calculation produced moment-to-moment distances and angular offsets to the future position of a turning vehicle (i.e., $r, \theta$ pairs). The analysis thus attempts to determine the distribution of distances and angles along a turn trajectory for which a driver might need adequate illumination to enable sufficient time to stop the vehicle to avoid an object in the turn path.

The vehicles used in the RDCW field test were 2003 Nissan Altima 3.5 SE sedans outfitted with on-board data acquisition systems capable of recording GPS information.

\section{Subjects}

The turning behavior of 87 drivers was analyzed. The pool of drivers included 47 male and 40 female drivers. They were divided into three age groups: young (20 to 30 years, 32 total); middle (40 to 50 years, 28 total); and old (60 years and older, 27 total).

\section{Analysis}

Turn Selection Criteria. Turn trajectories of a fleet of instrumented 2003 Nissan Altima 3.5SE sedans was recorded using a global positioning system (GPS) to provide latitude and longitude coordinates, along with measures of vehicle speed, heading angle, and yaw rate, recorded at a fixed rate of $10 \mathrm{~Hz}$. Turns were initially detected by scanning vehicle time histories for yaw rates that exceeded a minimum of 8 degrees per second, and then tracking backward and forward in the time history for yaw rates below 0.5 
degrees per second, defining the start and stop of the turn, respectively. Turns that exceeded $35 \mathrm{mph}(56 \mathrm{~km} / \mathrm{h})$ during this interval were removed from the sample. Turns located on limited access roads and freeway ramps were also removed from the samplein most cases, these turns exceeded the low speed turn criterion for cornering lamp operation; turns on local roads, and on major and minor surface streets were retained. The turn sample was also filtered to include only turns in which there occurred a heading change of between 45 and 150 degrees. Finally, turns involving excessive GPS dropouts were also removed from the sample. Thus, the selected turns were expected to conform to the general operating environment implied in SAE J852 and ECE R119.

Data Processing. The distribution of total heading change included in the sampled turns was calculated to provide an overview of the general characteristics of turns examined in this analysis. In addition, a breakdown of the average number of turns by age group and gender was also developed to further characterize the sample of turns.

Each sampled GPS coordinate in the turn trajectory was transformed to rectangular metric coordinates. These coordinates, which represent the center of a vehicle, were split into separate trajectories to represent the approximate lateral offset of a cornering lamp mounted to each side of a vehicle. For the Altima, trajectories were defined for left and right offsets from the center of the vehicle based on a vehicle width of $1.8 \mathrm{~m}$. Thus, a left-side and right-side trajectory was computed for each turn. Based on the measured vehicle speed, a future stopping time was calculated for each point in the turn trajectory based on a uniform deceleration of $0.3 \mathrm{~g}\left(2.94 \mathrm{~m} / \mathrm{s}^{2}\right)$. An angular heading offset and distance was calculated from the current vehicle position to the vehicle's future position at the stopping time offset (shown in Figure 3). For left turns, this calculation used the left-side vehicle trajectory; for right turns, the right-side trajectory was used. This reduced the effective vehicle turn radius by half the width of the vehicle. The points were then weighted by vehicle speed to weight turns by distance travelled (instead of time spent in the turn). For example, if one vehicle is travelling twice the speed of another, when sampled at $10 \mathrm{~Hz}$, the slower moving vehicle will produce twice the number of samples over the same distance. If the unweighted observations were then combined, the low-speed trajectory would have twice the weight of the high speed 
observations. After weighting points by vehicle speed, the results reflect the distance travelled (rather than time spent) at that trajectory.

For each subject, the distribution of weighted angular offsets and distances was compiled separately for left and right turns. These distributions were then normalized for each subject and combined so that subjects contributed equally to the overall distributions. That is, the raw number of turns a subject executed did not affect the weight of that subject's data in the overall distribution.

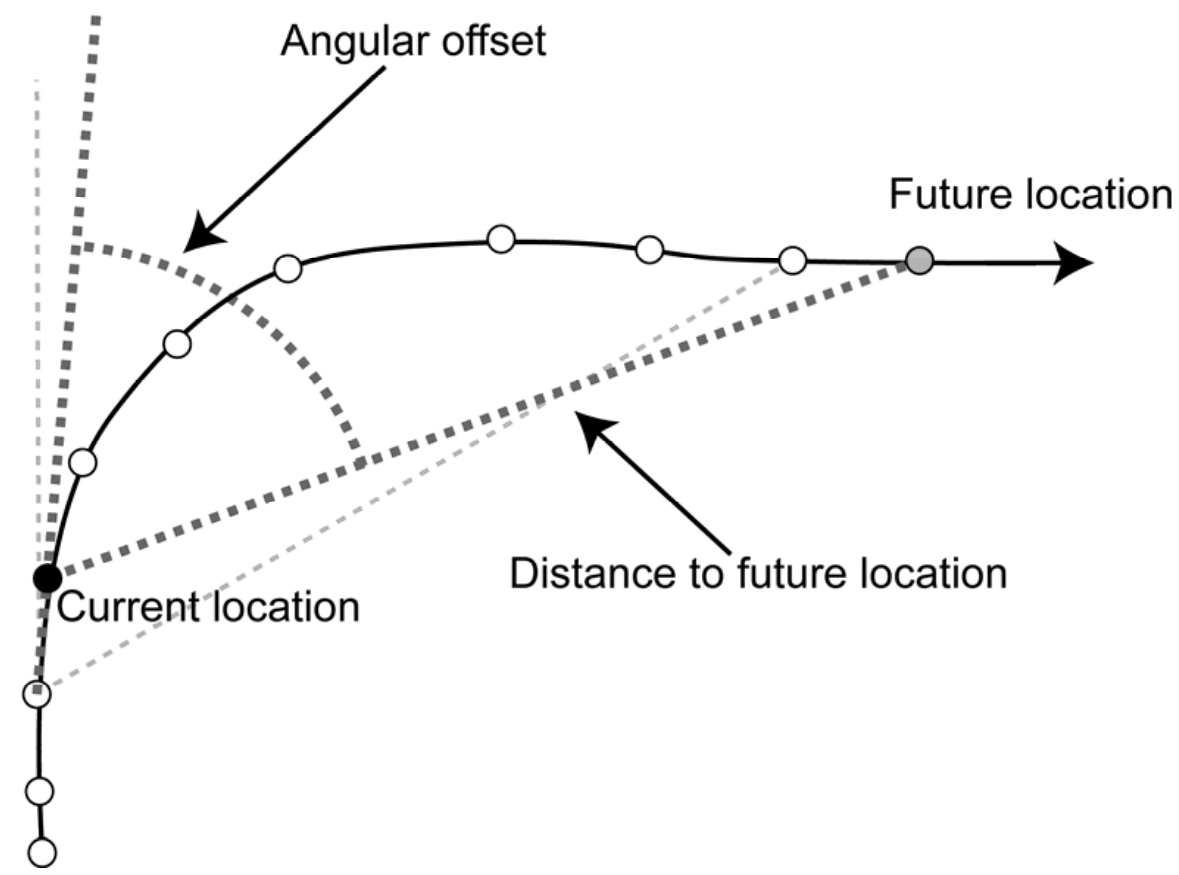

Figure 3. Calculation of distance and angular offset for each point in the path of a turning vehicle. The future location is determined by the calculated time required to bring the vehicle to a stop. 


\section{Results}

Distribution of Heading Change. The distribution of heading changes in the sample of turns is shown in Figure 4. The abrupt cutoff at \pm 40 degrees reflects the filtering criteria applied to the sample. A similar cutoff was also applied to turns above \pm 150 degrees, although less than $5 \%$ of turns exceeded a heading change of 120 degrees. Turns of 90 degrees dominated the sample, which appeared to be symmetrically skewed toward smaller heading changes.

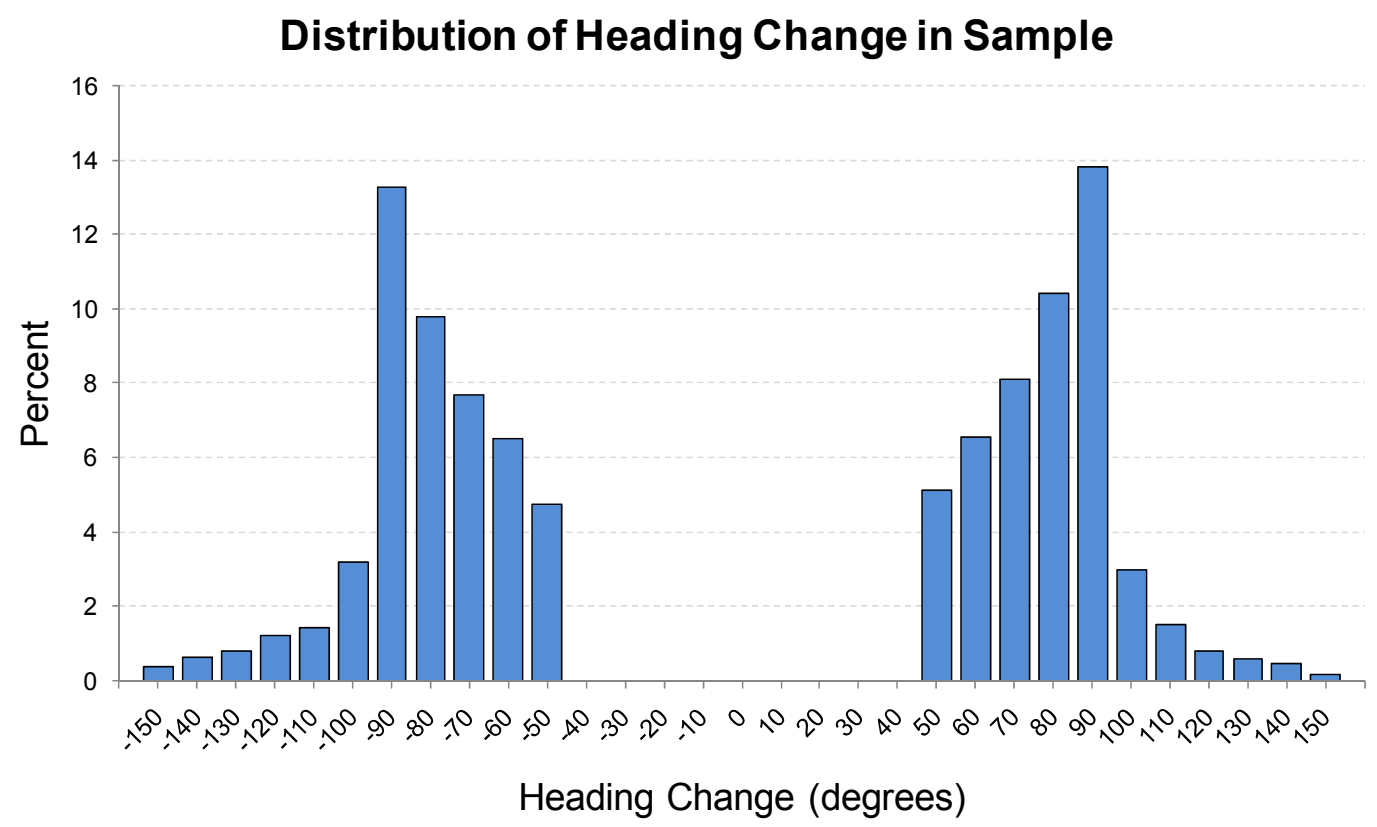

Figure 4. Distribution of heading change among drivers in sample. Right turns are indicated by positive heading change, left turns are negative heading changes. The bars in the histogram sum to 100 percent.

Turn Count by Age, Sex, and Direction. In the driver sample, younger drivers produced more turns on average than either the middle aged or older drivers. Older and middle aged females also produced fewer turns than their male counterparts. These differences do not necessarily reflect different propensities to execute turns among the subjects, but instead mirror overall differences in the amount of driving performed during the four-week period of the field test (LeBlanc et al., 2006). Younger drivers produced slightly more left turns in the sample than right turns, unlike middle aged and older drivers. The differences in turn quantities were offset by separately calculating 
distributions within age group, sex, and turn direction and then combining them with equal weight.

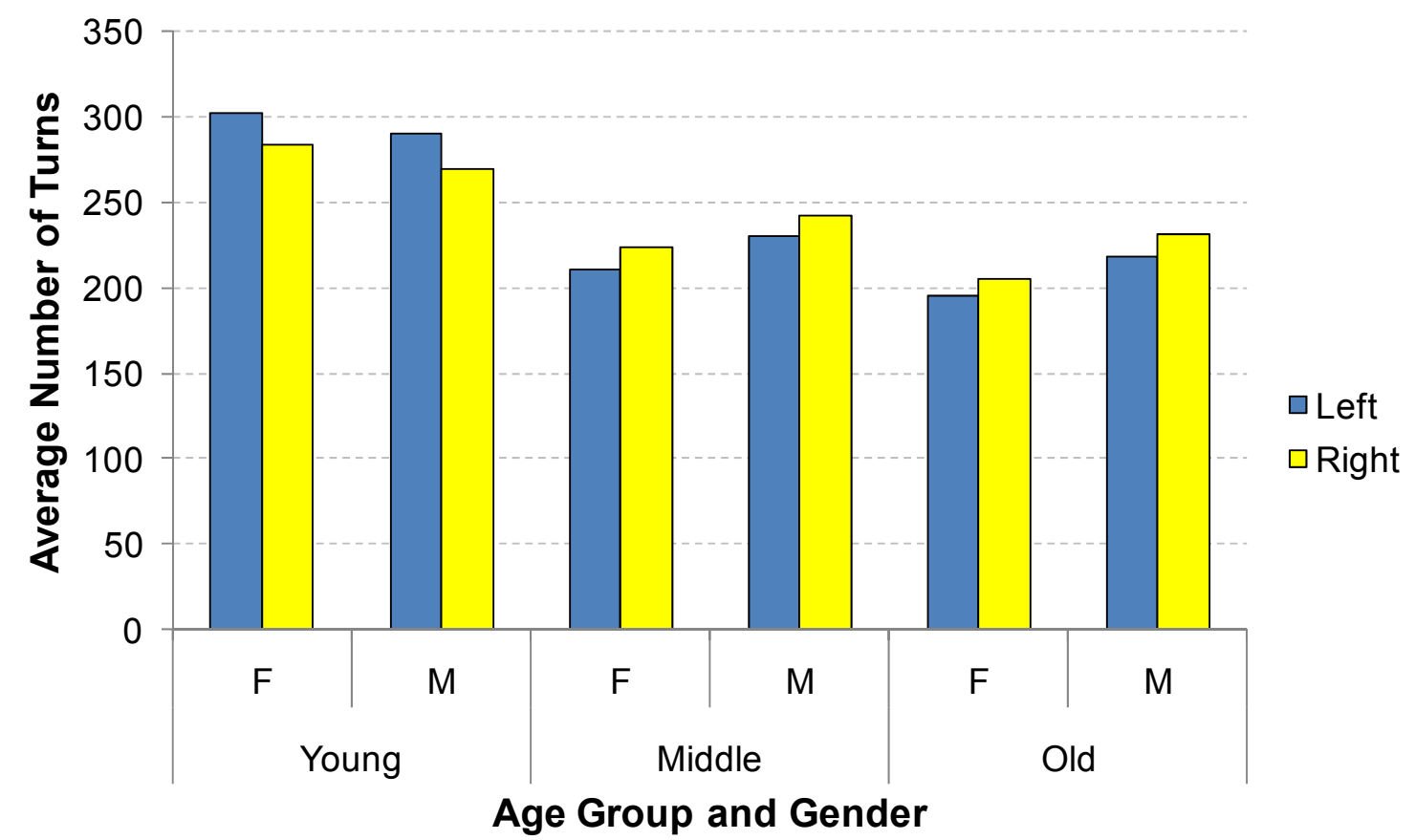

Figure 5. Average number of turns by direction, driver age, and gender. 
Distribution of Future Position along a Turn Trajectory. Figure 6 provides a contour map of the distribution of the future positions of a vehicle, relative to the current position based on turn trajectories compiled from the RDCW database of naturalistic driving data. The future position was determined by calculating the time it would take to stop a vehicle, given its current speed and assuming a brake initiation latency of $1.5 \mathrm{sec}$ and a deceleration rate of $0.3 \mathrm{~g}\left(2.94 \mathrm{~m} / \mathrm{s}^{2}\right)$. It is important to recognize that Figure 6 does not represent vehicle path trajectories. The six red markers along the 30, 45, and 60 degree radials (left and right) identify the approximate position of where the photometric minimum points intersect the ground plane. This calculation is based on an assumed mounting height of 0.46 meters, the average mounting height associated with fog lamps (Schoettle, Sivak, \& Nakata, 2002), and both the SAE and ECE locations of photometric minimum points. As can be seen in Figure 6, these points do not appear to be well aligned with the future position of turning vehicles.

It is also noteworthy that the left and right distributions appear to be bimodal, with peaks near each lamp's origin as well as peaks approximately 15 meters away at around \pm 32 degrees. The bimodal distribution is a likely consequence of whether the turn is initiated from a stop, or whether it is part of a continuous transition between a straight direction of travel followed by a turn - as when turning at an intersection with a green traffic signal. To examine this in more detail, the distribution of vehicle speed at the start of each turn was compiled across the sample (shown in Figure 7). As expected, the initial speed distribution is also bimodal, suggesting that some turns are initiated after the vehicle stopped, while others are initiated without a stop.

There also appears to be some asymmetry in the left and right distributions of future vehicle offset. For example, the right turn distribution suggests a need for path illumination at near distances at offset angles less than 15 degrees, while in left turns, path illumination at near distances would be more suited at angular offset between 15 and 30 degrees. One reason for this difference may that the characteristics of turn execution in each direction are markedly different. For example, at signalized intersections it is generally permissible to make a right turn on red after stopping, while left-turning vehicles are required to stop and remain stopped. It is possible that right-turning vehicles frequently creep through intersections when a stop is signaled, without actually coming to 
a full stop. In such a case, the lead-up to the turn might involve low speeds and small angular deviations until a sufficient gap is detected to allow merging into the flow of crossing traffic. This pattern is less likely to occur in left turns.

Another difference between the left and right turns is that the distribution of future positions in left turns extends farther distances along the radial with less acute angular offsets (i.e., close to the -30 degree radial). In contrast, the right turn distribution suggests slightly larger angular offsets and nearer future positions. This is likely related to differences in the average turn radius of left versus right turns. Left turns, with larger turn radii, might support traversal at slightly higher vehicle speeds and less acute angular deviations. 


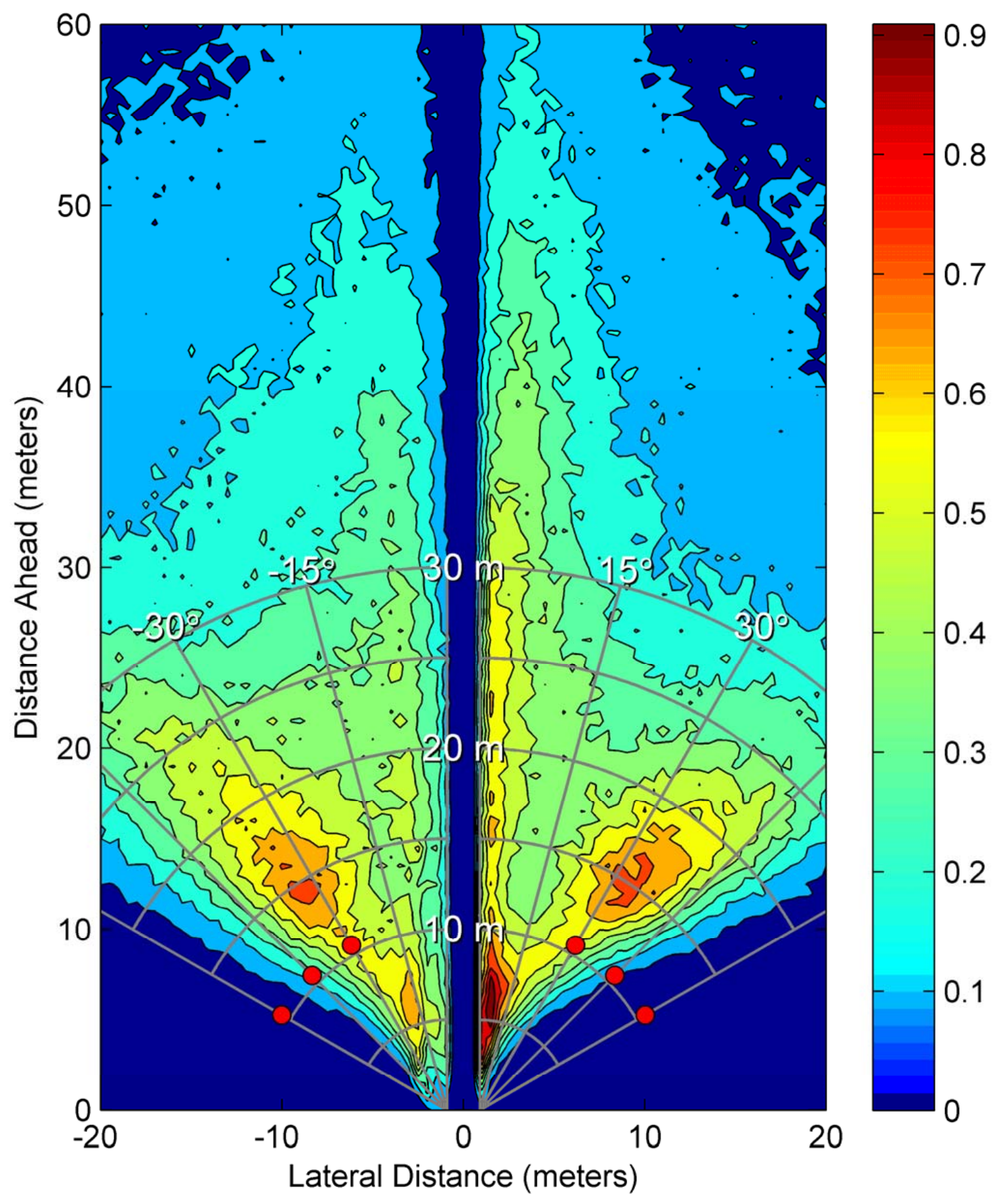

Figure 6. Birds-eye view of projected future locations. The three red points to each side indicate the projected pavement locations of minimum photometric test points described in both the SAE J852 Recommended Practice and ECE Regulation 119. The origin of the entire diagram $(0,0$ meters $)$ represents the midline/front of the vehicle. The slightly separate origins of the two grid overlays coincide with the approximate positions of left and right cornering lamps ( 0.8 meters to either side of the midline). The colored contours indicate relative density. 


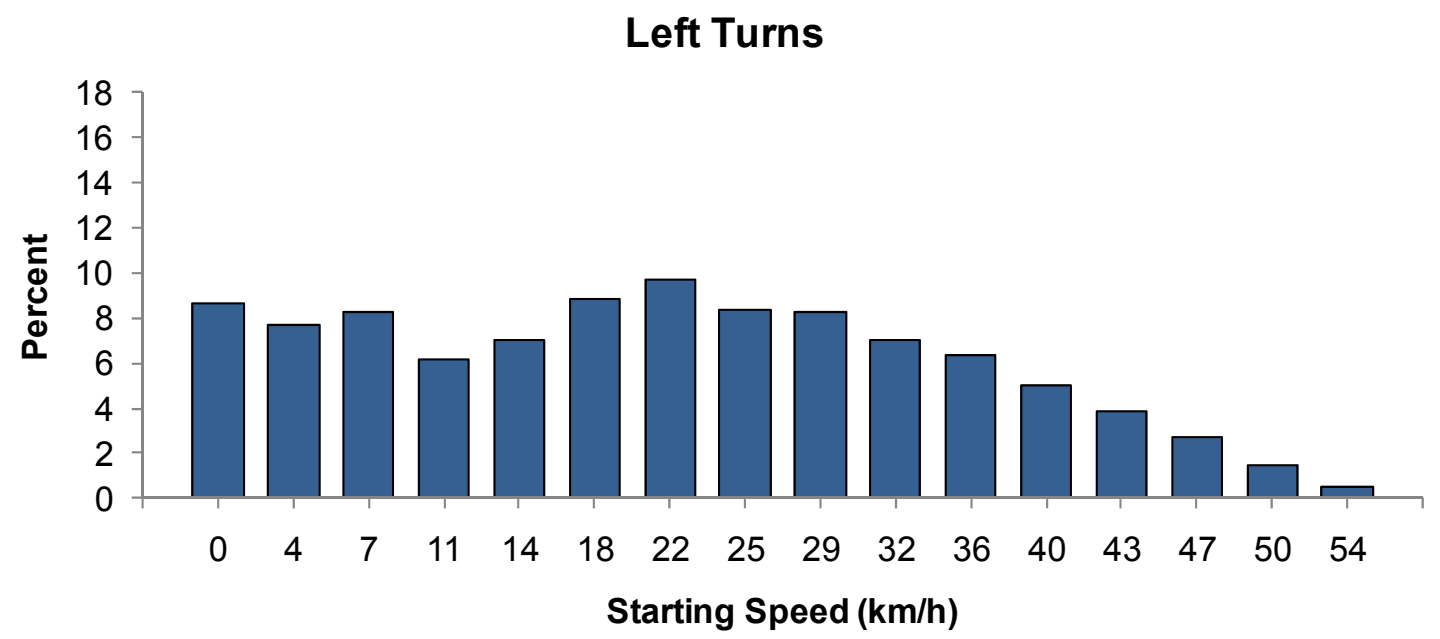

Right Turns

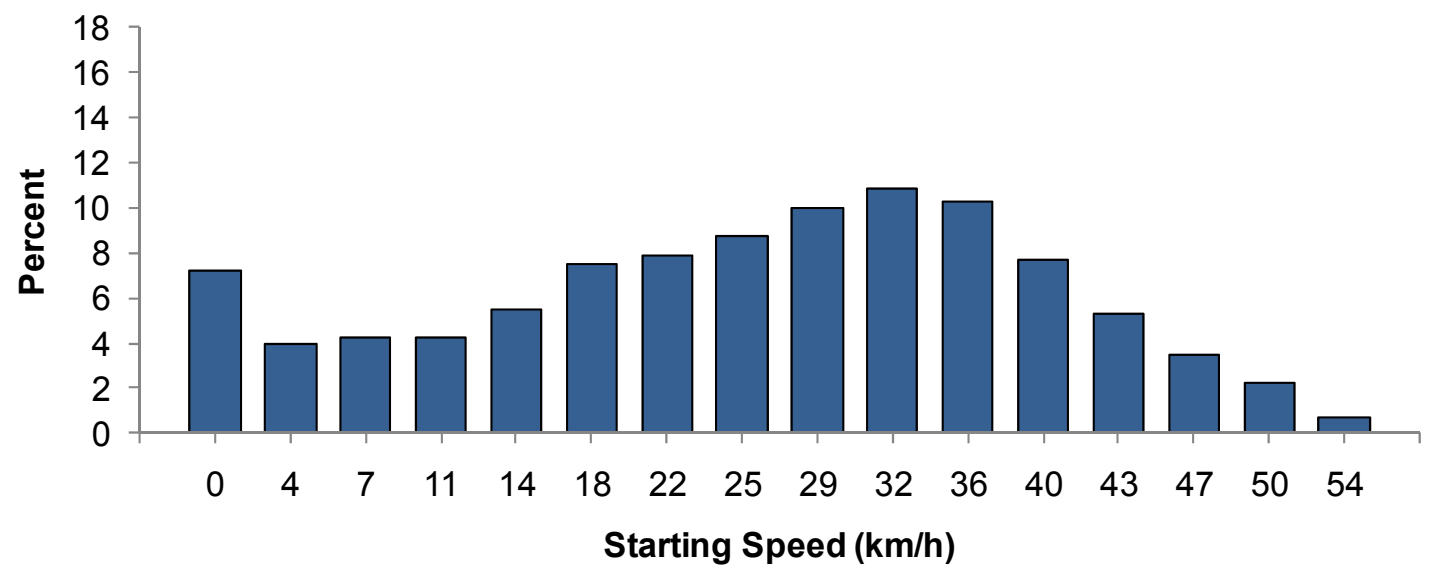

Figure 7. Vehicle speed at the start of a turn for left and right turns. The observed distributions are bimodal, suggesting turns initiated from stopped versus moving vehicles. 


\section{Conclusion}

This analysis of the distribution of future locations along a turn path is the first examination of turn kinematics performed by drivers under natural conditions. The results seem to suggest that both SAE J852 and ECE R119/48 may be a less-than-perfect matches to a driver's needs, if illumination of the turn trajectory were the primary objective of cornering lamps. For example, the downward aim of the highest minimum test points $(2.5 \mathrm{D}, 45 \mathrm{~L}$ and $45 \mathrm{R})$ would intersect the roadway short of the peak future path locations on both the left and right sides, unless the mounting height of the lamp exceeded $700 \mathrm{~mm}$. Such height is close to the range limit indicated in SAE J582 and is well above the center of the range indicated in ECE R48. This being said, it should be noted that there are no maximums in SAE J852 below H, while ECE R119 fixes a maximum of $600 \mathrm{~cd}$ at $.57 \mathrm{D}$ and $10,000 \mathrm{~cd}$ below $.57 \mathrm{D}$, thus clearly permitting illumination to reach this range while complying with each specification. It should also be noted that the angular offsets of the minimum photometric points described in the two specifications are not well aligned with the actual distribution of future positions within the turns examined in this dataset. In both SAE J582 and ECE R119, the photometric points are centered around $45 \mathrm{~L}$ and $45 \mathrm{R}$, while the future position data appears to suggest the future path is centered around $32 \mathrm{~L}$ and $32 \mathrm{R}$ for moving turns, and below 30 $\mathrm{L}$ and $15 \mathrm{R}$ for turns initiated from stops or near-stops.

Of course, there are also many important objects to view around a roadway that are not in the travel path of the turning vehicle. This includes fixed objects such as lane and roadway boundary markings and signage positioned beside the road, some of which may not be reflectorized; it also includes objects such as pedestrians, pedalcyclists, and animals that may wander into the travel path of the vehicle. The present data do not specifically address these circumstances, although further modeling of the geometric characteristics may provide some guidance in optimizing the cornering light distribution for the driver. 


\section{References}

LeBlanc, D., Sayer, J., Winkler, C., Ervin, R., Bogard, S., Devonshire, J., et al. (2006). Road departure crash warning system field operational test: methodology and results. Volume 1: technical report. (Technical Report No. UMTRI-2006-9-1). Ann Arbor: University of Michigan Transportation Research Institute.

Schoettle, B., Sivak, M., \& Nakata, Y. (2002). The locations of signalling and lighting equipment on passenger vehicles sold in the U.S. (Technical Report No. UMTRI2002-8). Ann Arbor, MI: The University of Michigan Transportation Research Institute.

Society of Automotive Engineers. (2001). Front cornering lamps for use on motor vehicles. (Surface Vehicle Recommended Practice No. J852). Warrendale, PA: Society of Automotive Engineers.

The Old Car Manual Project. (2010). Retrieved June 9, 2010, from http://www.oldcarmanualproject.com/brochures/Cadillac/1962/pages/cad6212x jpg.htm.

United Nations Economic Commission for Europe. (2005). Uniform provisions concerning the approval of cornering lamps for power-driven vehicles. (Regulation No. 119). Geneva: United Nations Economic Commission for Europe.

United Nations Economic Commission for Europe. (2008). Uniform provisions concerning the approval of vehicles with regard to the installation of lighting and light signalling devices. (Regulation No. 48). Geneva: United Nations Economic Commission for Europe. 